\title{
Os Cursos de Pedagogia da Universidade Estadual Paulista e a EdUCAÇÃo INCLUSIVA ${ }^{1}$ \\ The Courses of Pedagogy at Universidade Estadual Paulista and INCLUSIVE EDUCATION
}

\author{
Cristiane Regina Xavier FONSECA-JANES² \\ Sadao OMOTE ${ }^{3}$
}

\begin{abstract}
RESUMO: a educação inclusiva é tida como uma educação de qualidade que deve ser oferecida pelo sistema educacional a todas as crianças, jovens e adultos. Para a efetivação de tal proposta, dentre várias necessidades, precisamos de recursos humanos qualificados para o enfrentamento desse desafio. Este trabalho tem por objetivo analisar as matrizes curriculares dos cursos de Pedagogia da Universidade Estadual Paulista para a formação em uma perspectiva inclusiva. Para isto, foram analisados os projetos políticopedagógicos dos seis cursos de Pedagogia, as Resoluçóes da UNESP que os regulamentam e trechos de entrevistas realizadas com os coordenadores dos respectivos cursos. Para análise das matrizes, as disciplinas obrigatórias foram distribuídas em um quadro com as seguintes categorias: 1) disciplinas específicas relacionadas com a Educação Inclusiva, 2) carga horária das disciplinas relacionadas com a Educação Inclusiva, 3) disciplinas específicas relacionadas com a Educação Especial e 4) carga horária das disciplinas relacionadas com a Educação Especial. Dos seis cursos de Pedagogia da UNESP, cinco possuem disciplinas voltadas para a questão da Educação Inclusiva, com as mais diversificadas cargas horárias, e quatro possuem disciplinas voltadas para questôes específicas da Educação Especial.
\end{abstract}

PALAVRAS-CHAVE: Educação Inclusiva. Educação Especial. Grade Curricular. Curso de Pedagogia.

\begin{abstract}
Inclusive education is seen as quality education that should be provided by the educational system for all children, young people and adults. In order to put such a proposal into effect, qualified personnel are needed who are equipped to face such a challenge. This paper aims to examine the curriculum matrices of Pedagogy courses of the Universidade Estadual Paulista - UNESP that intend to prepare future teachers to follow an inclusive perspective. To this end, the political-pedagogical projects of six Pedagogy courses, the University resolutions that regulate the courses and excerpts taken from interviews carried out with course coordinators were analyzed. In order to analyze the curriculum matrices, the required subjects were distributed on a table according to the following categories: 1) specific subjects related to inclusive education, 2) number of hours of each subject related to inclusive education, 3) specific subjects related to special education and 4) amount of time scheduled for each subject related to special education. Among the six Pedagogy courses, five had subjects that focused on issues related to inclusive education, with varying time allotments, and four had subjects focusing on specific issues related to special education.
\end{abstract}

KEYWORDS: Inclusive Education. Special Education. Curriculum. Pedagogy Course.

\section{INTRODUÇÃo}

A Educação Inclusiva é mais do que a retirada dos obstáculos que impedem alguns alunos de freqüentarem a escola regular; antes de tudo, é um processo dinâmico sem

\footnotetext{
${ }^{1} \mathrm{O}$ projeto de pesquisa conta com o financiamento da Fundação de Amparo à Pesquisa do Estado de São Paulo-FAPESP (Processo $\left.\mathrm{n}^{\circ} 2011 / 00501-4\right)$.

${ }^{2}$ Bolsista de pós-doutoramento pela FAPESP. Pesquisadora do Grupo de Pesquisa Diferença, Desvio e Estigma. Doutora em Educação, mestre em Filosofia e Pedagoga com habilitação em Educação Especial, pela Universidade Estadual Paulista - UNESP, Faculdade de Filosofia e Ciências, Campus de Marília. crisrefonseca@itelefonica.com.br

${ }^{3}$ Professor Titular e Docente do Programa de Pós-Graduação em Educação da Faculdade de Filosofia e Ciência da Universidade Estadual Paulista - UNESP, Campus de Marília. Líder do Grupo de Pesquisa Diferença, Desvio e Estigma. Bolsista de Produtividade em Pesquisa 1-C. somote@uol.com.br
} 
término, uma vez que não é um mero estado de mudança, mas um processo de reestruturação educacional tanto organizacional quanto pedagógico contínuo. Tal processo ainda está em construção e é passível de transformação e ressignificação. A Educação Inclusiva implica uma reforma radical no sistema educacional, uma vez que necessita reestruturar os seus sistemas curriculares, avaliativos e didático-pedagógicos. Essa reforma educacional precisa garantir que todos os alunos tenham acesso ao ensino regular e nele permaneçam com bom aproveitamento, oferecendo estratégias para se impedir a segregaçáo e o isolamento dos alunos.

Para que o sistema educacional, mediante tal reforma radical, consiga prover ensino de qualidade a todos os alunos, é necessário o uso de recursos especiais, muitas vezes destinados a uma parcela muito pequena do alunato, aquela representada por alguns alunos que podem apresentar peculiaridades muito especiais no seu desenvolvimento e aprendizagem, decorrentes não de diferenças socioculturais ou linguísticas, mas resultantes de patologia ou traumatismos que produzem alteraçóes expressivas no seu funcionamento. Essas peculiaridades podem constituir-se em enorme dificuldade ou até mesmo impedimento para a realização de determinadas atividades no seu processo de aprendizagem. Muitos dos alunos com esse perfil podem ser escolarizados mediante o uso de recursos especiais: didáticos, programáticos e de comunicaçáo. $\mathrm{O}$ uso de tais recursos especiais para prover ensino de qualidade a alunos com comprometimentos severos que dificultam acentuadamente ou impedem a aprendizagem por meios convencionais utilizados pela maioria do alunato se constitui em domínio da Educação Especial.

Pode-se dizer que, para a prática integral da Educação Inclusiva, os recursos de Educação Especial, inclusive os recursos humanos, representados por professores especializados no ensino de alunos com deficiências, se constituem em elementos indispensáveis. Sem os recursos de Educação Especial, alunos com graves deficiências podem ter dificuldades de acesso à educação de qualidade ou de permanecer nela com o devido proveito. Quanto mais se fortalece e consolida a Educação Inclusiva, mais necessários são os recursos de Educação Especial.

A posição assumida pelos autores neste texto é a de que a Educação Especial faz parte integrante e solidária para a efetivação da Educação Inclusiva. À parte da Educação Inclusiva, a Educação Especial corre o risco de desenvolver práticas segregativas, como ocorreu no passado recente nas propostas do movimento integracionista no Brasil. $\mathrm{Na}$ educação de alunos com severos comprometimentos ou mesmo impedimentos, decorrentes de alteraçóes constitucionais expressivas devidas a patologias e traumatismos, é essencial ter como norte os princípios da Educação Inclusiva, sob pena de promover a segregação desses alunos.

Constitui-se como princípio basilar aqui a idéia de que a educação de alunos com deficiência, independentemente do grau e da natureza do comprometimento, deve ser realizada em ambiente escolar comum, em conjunto com seus pares coetâneos, desde que tal condição não se constitua em impedimento para oferecer ensino de qualidade a eles. Portanto, pode-se admitir a possibilidade de alunos com deficiência receberem ensino de qualidade integralmente em ambientes de ensino comum, mesmo com a utilização de recursos especiais e diferenciados, até totalmente em ambientes especiais constituídos somente para alunos que têm essa necessidade. Para cada aluno deve ser oferecida condição adequada que garanta o ensino de qualidade, no gradiente que varia entre esses extremos, capaz de atender da melhor maneira 
possível as suas necessidades especiais. E isto é possível com o uso criterioso e pleno dos recursos de Educação Especial.

Os estudiosos das questóes concernentes à Educação Especial e à Educação Inclusiva sugerem que se produzam pesquisas científicas bem fundamentadas e passíveis de replicação. Estas pesquisas devem ter como perspectiva a criação de estratégias metodológicas a serem desenvolvidas em sala de aula, políticas públicas sérias e que sejam eficientes na questão da inclusão e gestão competente para fortalecer o sistema regular de ensino, de forma que os alunos pertencentes aos grupos minoritários, independentemente de suas características singulares, possam ingressar, permanecer e aprender em uma escola de qualidade.

Essa perspectiva não difere das metas traçadas por todos aqueles que visam a uma educação democrática de qualidade, gratuita e laica, desde o Manifesto dos Pioneiros de 1932 ou mesmo o Manifesto dos Educadores Mais Uma Vez Convocados de 1959. Ao se falar em educação de qualidade, uma questão fundamental diz respeito à formação de professores, uma vez que a eles cabe a responsabilidade de proporcionar as estratégias sistematizadas e planejadas para que seus alunos efetivem o processo de aprendizagem. A Educação Inclusiva é um ideal para todos os níveis de ensino, mas o presente estudo enfocou a formação do pedagogo, uma vez que é no curso de Pedagogia que se formam os profissionais para atuarem na docência da Educação Infantil e do Ensino Fundamental, bem como os gestores educacionais.

O curso de Pedagogia no Brasil foi criado pelo Decreto $n^{\circ} 1.190$, de 4 de abril de 1939 (BRASIL, 1939), na Faculdade Nacional de Filosofia. Originalmente se estruturou como um curso de bacharelado com duração de três anos e a licenciatura, com mais um ano, por meio do curso de Didática, o famoso esquema de “ $3+1$ ", que compóe a maioria dos cursos de bacharelado e licenciatura.

A literatura sobre o histórico do curso de Pedagogia evidencia que essa regulamentação de 1939 tinha como incumbência formar os técnicos educacionais, pois os interessados no curso eram pessoas que pleiteavam o ingresso em funçóes de administrador, avaliador e orientador educacional, planejador curricular, inspetor de escolas e pesquisador tecnológico educacional junto ao MEC, às secretarias dos estados e às dos municípios. O curso formava bacharéis e licenciados. O pedagogo com bacharelado era o técnico educacional e com licenciatura era o professor de matérias pedagógicas.

Com a aprovação da Lei n o. 4024, de 20 de dezembro de 1961 (BRASIL, 1961), a primeira Lei de Diretrizes e Bases da Educação Nacional, houve uma reestruturação curricular no curso de Pedagogia. Tal curso passou de três para quatro anos e os egressos eram titulados como bacharéis e licenciados. Na opiniāo de Saviani (2007), a nova reestruturação curricular do curso manteve seu caráter generalista por não haver ainda as habilitaçóes.

Em 1968, ocorreu a Reforma Universitária que deliberou ser facultativo ao curso de Pedagogia oferecer as habilitaçóes em Supervisão, Administração e Inspeção Educacional e outras especialidades. Já a Resolução do Conselho Federal da Educação no ${ }^{\circ}$ 2, de 12 de maio de 1969 (BRASIL, 1969), determinou que o curso de Pedagogia fosse responsável pela formação de professores para o Ensino Normal, orientadores, administradores, supervisores e inspetores educacionais. 
A partir da década de 80, por influência das pesquisas educacionais e reivindicaçóes de movimentos populares, algumas Faculdades de Educação "suspenderam ou suprimiram as habilitaçóes convencionais [...], para investir num currículo centrado na formação de professores para as séries iniciais do ensino fundamental e curso de magistério" (LIBÂNEO, 1998, p. 38). Assim, o curso de Pedagogia começa a ganhar a especificidade de formação de profissionais para docência. Quanto à educação infantil com finalidade educativa só emerge na Lei de Diretrizes e Bases no. 9394, de 20 de dezembro de 1996 (BRASIL, 1996).

A história do curso de Pedagogia revela que, com a aprovação das Diretrizes Curriculares Nacionais de 15 de maio de 2006, se estabeleceu o perfil do egresso a ser formado no curso de Pedagogia (BRASIL, 2006). Assim, esse curso pode ser considerado o locus de formação inicial dos profissionais que atuam na docência da Educação Infantil e nos anos iniciais do Ensino Fundamental, bem como na gestão de sistemas educacionais. Entretanto, essa definiçãao de atuação dos pedagogos não se constituiu de maneira clara, calma e tranqüila. Embates políticos e epistemológicos ocorreram para que fosse construída essa quase consensual definição do seu campo de atuação.

A Universidade Estadual Paulista "Júlio de Mesquita Filho" (UNESP) é uma das três universidades públicas mantidas pelo governo do Estado de São Paulo. A UNESP está presente em todas as regióes paulistas, sendo 32 unidades em 23 cidades. Essas unidades formam aproximadamente 6 mil novos graduados por ano, com a opção de 171 cursos de graduação em 62 profissóes de nível superior. Dentre essas profissóes, encontra-se a do Pedagogo, que é formado no curso de Pedagogia, oferecido em seis unidades diferentes: 1) Faculdade de Ciências do Campus de Bauru, 2) Faculdade de Ciências e Letras do Campus de Araraquara, 3) Faculdade de Ciências e Tecnologia do Campus de Presidente Prudente, 4) Faculdade de Filosofia e Ciências do Campus de Marília ${ }^{4}$, 5) Instituto de Biociências do Campus de Rio Claro e 6) Instituto de Biociências, Letras e Ciências Exatas do Campus de São José do Rio Preto.

A UNESP foi a universidade pública pioneira na formação de professores especializados para o ensino de pessoas com deficiência, oferecendo a habilitação em Educação Especial desde 1977. Inicialmente essa habilitação era oferecida na Faculdade de Filosofia e Ciências no Campus de Marília e, a partir de 1986, também passa a ser oferecida pela Faculdade de Ciências e Letras no Campus de Araraquara (OMOTE, 1996). Com as Diretrizes Nacionais para o curso de Pedagogia, encerra-se a formação em habilitaçóes. O curso de Pedagogia da Faculdade de Filosofia e Ciências de Marília formou a sua última turma de professores especializados em 2010 e o da Faculdade de Ciências e Letras de Araraquara oferece o eixo de formação em Educação Especial até o ano letivo de 2012.

Essas peculiaridades da UNESP, a de formar o pedagogo em todo o interior paulista e a de ser a universidade pública pioneira na formaçáo de recursos humanos para o exercício do magistério com pessoas deficientes, atestam a sua importância.

Conforme foi apontado num estudo anterior (FONSECA-JANES, 2010), os cursos de Pedagogia da UNESP, ao longo de sua trajetória histórica, se constituíram de três formas

\footnotetext{
${ }^{4}$ No início de sua constituição esta Faculdade era nomeada por Faculdade de Educação, Filosofia, Ciências Sociais e da Documentação, Campus de Marília.
} 
organizacionais diferenciadas. Do primeiro grupo fazem parte os cursos que se constituíram ainda nos Institutos Isolados de Ensino Superior e não sofreram interrupçóes em suas trajetórias institucionais com a criação da Universidade Estadual Paulista "Júlio de Mesquita Filho", em 1976, mediante a reuniáo daqueles Institutos, como é o caso dos cursos de Pedagogia de Araraquara e de Marília. A segunda forma de organização corresponde aos cursos criados nos Institutos Isolados de Ensino Superior que tiveram descontinuidade com a criação da UNESP, sendo reabertos posteriormente, como é o caso dos cursos de Pedagogia de Presidente Prudente, de Rio Claro e de São José do Rio Preto. A terceira forma de organização é representada por um único curso, criado após a consolidação desta Universidade, o curso de Pedagogia de Bauru.

$\mathrm{Na}$ busca de fundamentos para fomentar as discussões sobre o processo de formação dos profissionais a trabalharem com os desafios que a oferta de uma educação de qualidade possa implicar, este trabalho tem por objetivo discutir a diversidade que compóem as matrizes curriculares dos cursos de Pedagogia da UNESP e refletir em que medida a formação do pedagogo está direcionada para a futura atuação em uma perspectiva inclusiva.

\section{Método}

\section{Participantes}

Participaram deste estudo os seis coordenadores dos Conselhos de Curso de Pedagogia da UNESP, que se encontravam em exercício da coordenação no período da reformulação do curso de Pedagogia no ano de 2006.

A idade dos coordenadores variou de 49 a 58 anos, com média de 53 anos e desvio padrão de 3,67, sendo três do gênero feminino e três do gênero masculino. Esses coordenadores tinham os seguintes perfis de formação: 1) graduação em Pedagogia, mestrado em Psicologia Social e doutorado em Educação; 2) graduação em Educação Especial para o Deficiente da Áudio-comunicação, mestrado, doutorado e pós-doutorado em Educação; 3) graduação em Filosofia, mestrado e doutorado em Educaçáo; 4) graduaçáo em Psicologia, mestrado e doutorado em Psicologia, pós-doutorado nos Estados Unidos da América e Livre-docência pela Universidade Estadual Paulista; 5) graduação em Pedagogia, mestrado e doutorado em Educação e Livre-docência pela Universidade Estadual Paulista; e 6) graduação em Psicologia e Filosofia, mestrado e doutorado em Educação. ${ }^{5}$

\section{Material}

Foi utilizado um roteiro de entrevista semiestruturado contendo identificação do coordenador do curso e dez questóes sobre o processo de adequação do curso de Pedagogia às exigências das Diretrizes Curriculares Nacionais, sobre a temática da Educação Inclusiva e sobre a Educação Especial. Os dados também foram coletados nos projetos político pedagógicos dos seis cursos de Pedagogia e em documentos oficiais da Universidade, destacando as Resoluçóes da UNESP no 16, de 29 de março de 2007, no 17, de 29 de março de 2007, no 18, de 29 de março de 2007, no 20, de 03 de abril de 2007, no 60, de 28 de agosto de 2007, no 82, de 27

${ }^{5}$ As informações foram retiradas do currículo Lattes dos participantes. 
de novembro de 2007, e no 45, de 25 de junho de 2009 (UNIVERSIDADE ESTADUAL PAULISTA, 2007a, 2007b, 2007c, 2007d, 2007e, 2007f, 2009).

\section{Procedimentos}

Os dados referentes às matrizes curriculares dos cursos de Pedagogia foram analisados identificando as disciplinas específicas relacionadas com a Educação Inclusiva e as relacionadas com a Educação Especial, e as respectivas cargas horárias.

As disciplinas foram categorizadas a partir de seu título. Caso houvesse a presença de palavras que remetessem à Educação Inclusiva eram categorizadas como "Disciplinas Específicas voltadas para a Educação Inclusiva”. As disciplinas, cujos títulos contivessem palavras que remetessem às questóes pertinentes aos estudos da Educaçáo Especial, eram categorizadas como "Disciplinas Específicas voltadas para a Educação Especial".

As disciplinas que compóem a formação básica do estudante foram codificadas como "DFB - Disciplinas de Formação Básica". As disciplinas que compóem o núcleo de formação específica dos estudantes foram codificadas como "DAEE - Disciplinas de Aprofundamento em Educação Especial".

Foram utilizadas algumas informaçóes provenientes das entrevistas para a compreensão das razóes da presença de disciplinas de Educação Inclusiva ou Educação Especial nas matrizes curriculares aqui analisadas. ${ }^{6}$

\section{Resultados E discussáo}

A distribuição das disciplinas nas matrizes curriculares dos cursos de Pedagogia da UNESP evidencia de imediato que estas possuem perfis que expressam a diversidade própria da constituição de cada unidade de ensino ${ }^{7}$. Mesmo com essa diversidade e particularidades próprias de cada curso, foram identificadas disciplinas específicas direcionadas à Educação Inclusiva e Educação Especial, com a respectiva carga horária, para fins de análise. Seu resultado se encontra no quadro 1 .

\footnotetext{
${ }^{6}$ As informaçôes obtidas por meio das entrevistas são objeto de análise em um outro relato.

${ }^{7}$ A UNESP foi criada em 1976 com a reunião e reorganização das instituiçôes isoladas de ensino superior estaduais existentes em todo o Estado de São Paulo, os antigos Institutos Isolados de Ensino Superior. Cada unidade de ensino possui um perfil próprio em função da sua constituição histórica e da sua inserção nas comunidades local e regional.
} 
Quadro 1 - Distribuição das disciplinas relacionadas a Educação Inclusiva e a Educação Especial nos cursos de Pedagogia da Universidade Estadual Paulista, com a respectiva carga horária.

\begin{tabular}{|c|c|c|c|c|}
\hline $\begin{array}{l}\text { Unidades Univer- } \\
\text { sitárias }\end{array}$ & $\begin{array}{l}\text { Disciplinas Específicas } \\
\text { voltadas para a Educação } \\
\text { Inclusiva }\end{array}$ & Carga Horária & $\begin{array}{l}\text { Disciplinas Específicas voltadas } \\
\text { para a Educação Especial }\end{array}$ & Carga Horária \\
\hline $\begin{array}{l}\text { FC - Campus de } \\
\text { Bauru }\end{array}$ & $\begin{array}{l}\text { Educaçáo Inclusiva } \\
\text { (DFB) }\end{array}$ & $68 \mathrm{~h}$ & $\begin{array}{l}\text { Introdução ao Ensino da Língua } \\
\text { Brasileira de Sinais (DFB) }\end{array}$ & $68 \mathrm{~h}$ \\
\hline $\begin{array}{l}\text { FCL - Campus } \\
\text { de Araraquara }\end{array}$ & (1) & & Educação Especial (DFB) & $60 \mathrm{~h}$ \\
\hline $\begin{array}{l}\text { FCT - Campus } \\
\text { de Presidente } \\
\text { Prudente }\end{array}$ & $\begin{array}{l}\text { Fundamentos da Educação } \\
\text { Inclusiva (DFB) }\end{array}$ & $75 \mathrm{~h}$ & $\begin{array}{l}\text { Libras, Tecnologia da Informação } \\
\text { e Comunicaçáo na Educação } \\
\text { (DFB) }\end{array}$ & $75 \mathrm{~h}$ \\
\hline $\begin{array}{l}\text { FFC - Campus } \\
\text { de Marília }\end{array}$ & $\begin{array}{l}\text { Fundamentos da Educação } \\
\text { Inclusiva (DFB) }\end{array}$ & $75 \mathrm{~h}$ & $\begin{array}{l}\text { Desenho Universal, Acessibilidade } \\
\text { e Adaptaçóes (DFB) } \\
\text { Diversidade, Diferença e Defici- } \\
\text { ência: implicaçóes educacionais } \\
\text { (DFB) } \\
\text { Língua Brasileira de Sinais (DFB) } \\
\text { Currículo e as Necessidades Edu- } \\
\text { cacionais Especiais (DFB) } \\
\text { Desenvolvimento e Aprendiza- } \\
\text { gem: Especificidades das Pessoas } \\
\text { com Deficiências (DAEE) } \\
\text { Comunicação e Sinalização Di- } \\
\text { ferenciadas na Educação Especial } \\
\text { (DAEE) } \\
\text { Recursos e Estratégias Didáticas } \\
\text { na Educação Especial (DAEE) } \\
\text { Sexualidade e Deficiência (DAEE) } \\
\text { Lingüística Aplicada à Educação } \\
\text { Especial (DAEE) }\end{array}$ & $\begin{array}{l}30 \mathrm{~h} \\
45 \mathrm{~h} \\
75 \mathrm{~h} \\
90 \mathrm{~h} \\
90 \mathrm{~h} \\
60 \mathrm{~h} \\
30 \mathrm{~h}\end{array}$ \\
\hline $\begin{array}{l}\text { IB - Campus de } \\
\text { Rio Claro }\end{array}$ & $\begin{array}{l}\text { Fundamentos da Educaçáo } \\
\text { Inclusiva (DFB) }\end{array}$ & $75 \mathrm{~h}$ & - & - \\
\hline $\begin{array}{l}\text { IBiLCE - Cam- } \\
\text { pus de São José } \\
\text { do Rio Preto }\end{array}$ & $\begin{array}{l}\text { Tópicos de Educação Inclu- } \\
\text { siva (DFB) }\end{array}$ & $45 \mathrm{~h}$ & - & - \\
\hline
\end{tabular}

Legenda:

O símbolo “_“ representa a ausência de disciplinas.

DFB - Disciplinas de Formação Básica.

DAEE - Disciplina de Aprofundamento em Educação Especial 
As disciplinas referentes a Educação Inclusiva possuem a mesma denominação de Fundamentos da Educação Inclusiva nos cursos de Pedagogia dos campus de Presidente Prudente, Marília e Rio Claro. Nestas unidades universitárias, essa disciplina tem cinco créditos (75 horas) e compóem o núcleo de formação básica dos estudantes. Já nos campus de Bauru e São José do Rio Preto, as disciplinas têm a denominação de Educação Inclusiva e Tópicos da Educação Inclusiva, com a carga horária de 68 e 45 horas, respectivamente. As disciplinas que podem ser caracterizadas como sendo da Educação Especial são oferecidas em quatro campus: Bauru, Araraquara, Presidente Prudente e Marília. Os de Rio Claro e São José do Rio Preto não oferecem disciplina dessa área.

O elenco de disciplinas e as respectivas cargas horárias constantes do Quadro 1 apontam uma ampla diversidade entre os cursos, refletindo claramente as peculiaridades de cada unidade universitária em termos da sua constituição histórica e inserção na comunidade local e regional. A grande exceção que destoa do conjunto é o curso de Marília, com a oferta de uma disciplina de Educação Inclusiva e nove de Educação Especial, perfazendo um total de 570 horas-aula. Nos demais cursos, é oferecida uma única disciplina de Educação Inclusiva (caso dos cursos de Rio Claro e de São José do Rio Preto), ou de Educação Especial (caso de Araraquara) ou uma disciplina de Educação Inclusiva e uma de Educação Especial (caso dos cursos de Bauru e de Presidente Prudente).

O exame das disciplinas de Educação Inclusiva sugere que, de um modo geral, parecem tratar de alguns fundamentos básicos, que podem ser ministrados em relativamente pouco tempo, de 45 a 75 horas-aula. Já as disciplinas de Educação Especial oferecidas nos cursos de Bauru e de Presidente Prudente parecem oferecer alguma capacitação ao futuro pedagogo para implementar algumas açóes específicas requeridas na educação de alunos com determinadas necessidades específicas, já que tratam da Língua Brasileira de Sinais, essencial para a educação de alunos surdos, e da Tecnologia de Informação e Comunicação, que oferece ampla possibilidade de utilização das modernas tecnologias, sobretudo computacionais, para favorecer o acesso a informação e a comunicação das pessoas com comprometimentos nessa competência

A cidade de Bauru tem uma forte tradição de serviços altamente especializados, incluindo a atenção a pessoas surdas, o que pode estar relacionado com a oferta de uma disciplina específica de Língua Brasileira de Sinais. Já no campus de Presidente Prudente, há um grupo de pesquisadores atuantes na área de informática aplicada à Educação, o que pode justificar a presença no curso de Pedagogia desse campus de disciplina que trata das tecnologias de informação e comunicação na Educação, juntamente com temas relacionados a Língua Brasileira de Sinais.

Nessa análise, é digno de nota o currículo do curso de Pedagogia de Araraquara, que oferece a disciplina Educação Especial, com 60 horas-aula, mas nenhuma disciplina relacionada à Educação Inclusiva; aliás é o único curso que não oferece disciplina sobre essa temática. Este campus tem uma longa tradição na atenção às pessoas com deficiência intelectual. Desde 1977, havia um grupo de professores empenhados em formar recursos humanos e estruturar serviços visando a oferecer serviços a pessoas com deficiência mental. A Habilitação em Educação Especial: Ensino de Deficientes Mentais, do campus de Araraquara, teve início em 1986 e foi desativada em função da recente reformulação do curso de Pedagogia, que extinguiu as habilitaçóes. No 
decorrer desses dez anos antes do início da Habilitação em Educação Especial, esse grupo de professores de Araraquara ofereceu cursos de capacitação, incluiu a disciplina Educação Especial no currículo do curso de Pedagogia e criou o Centro de Estudos, Assessoria e Orientação Educativa Dante Moreira Leite (CEAO). Do quadro assim constituído até a situação atual na qual é oferecida apenas a disciplina Educação Especial, o esmaecimento do potencial construído ao longo de três décadas pode dever-se, pelo menos em parte, à configuração que esses recursos assumiram, com especialização unicamente na área da deficiência intelectual. Esta questão será discutida adiante, quando for tratada a situação do campus de Marília.

Nos campus de Rio Claro e São José do Rio Preto, que não têm tradição em especial na atenção a pessoas com deficiência, os responsáveis pelos seus cursos de Pedagogia, procurando atender a demanda recente, introduziram, compreensivelmente, uma disciplina de Educação Inclusiva, mas não a de Educação Especial.

O curso de Pedagogia de Marília apresenta um perfil muito particular. As nove disciplinas de Educação Especial podem ser classificadas em aquelas que provêem predominantemente conhecimentos sobre alguns processos básicos e outras que tratam de recursos e métodos ou técnicas de intervenção. Na primeira categoria, podem ser incluídas as disciplinas de Diversidade, Diferença e Deficiência: Implicaçôes Educacionais, Desenvolvimento e Aprendizagem: Especificidades das Pessoas com Deficiências, Sexualidade e Deficiência e Linguistica Aplicada à Educaçâo Especial, perfazendo um total de 180 horas-aula. Na segunda categoria, podem ser incluídas as disciplinas de Desenho Universal, Acessibilidade e Adaptaçóes, Língua Brasileira de Sinais, Curriculo e as Necessidades Educacionais Especiais, Comunicação e Sinalização Diferenciadas na Educação Especial e Recursos e Estratégias Didáticas na Educação Especial, com um total de 315 horas-aula.

$\mathrm{Na}$ realidade, das nove disciplinas de Educação Especial oferecidas no curso de Marília, cinco fazem parte da formação básica dos estudantes, sendo obrigatórias para todos os alunos de Pedagogia. As outras quatro disciplinas são oferecidas no Aprofundamento em Educação Especial, no último semestre do curso, quando os alunos fazem opção pela área na qual pretendem fazer o seu aprofundamento. As disciplinas de formação básica e as de aprofundamento podem ser identificadas no Quadro 1.

No curso de Marília, mesmo os estudantes que não fazem opção pelo aprofundamento em Educação Especial têm 75 horas-aula de Fundamentos da Educação Inclusiva e mais 195 horas-aula de disciplinas da Educação Especial, no total de 270 horas-aula. Desse total, 165 horas-aula se referem a disciplinas que podem ser consideradas como sendo instrumentais, que provêem conhecimentos sobre recursos e métodos. Uma dessas disciplinas, Currículo e as Necessidades Educacionais Especiais, pode ser considerada de capital importância para o pedagogo por tratar justamente de questóes centrais na educação escolar de pessoas com deficiências. Assim, os pedagogos que se formam no curso de Marília recebem uma formação que talvez consiga atender o propósito da reformulação do curso de Pedagogia. Com referência especificamente a esse curso, Oliveira (2009b, p. 7) apontou que o intuito da reformulaçáo, após as Diretrizes Curriculares Nacionais, foi o de, em consonância com a perspectiva inclusiva, formar professores "preparados para identificar e receber, em suas classes, alunos com necessidades educacionais especiais”. 
Já os alunos que fazem opção pelo aprofundamento em Educação Especial cursam, além daquelas cinco disciplinas, no total de 270 horas-aula, oferecidas a todos os estudantes de Pedagogia, outras cinco disciplinas com 300 horas-aula, no total de dez disciplinas com a carga horária de 570 horas-aula. Desse elenco, cinco disciplinas (255 horas-aula) tratam de diferentes assuntos que podem permitir aos estudantes compreenderem questóes fundamentais e básicas de pessoas com necessidades especiais; outras cinco disciplinas (315 horas-aula) tratam de temática que pretende capacitar o futuro pedagogo a favorecer o acesso de alunos com deficiências a ensino de qualidade, por meio do uso de recursos e procedimentos especiais e da adaptação de recursos, métodos e técnicas, currículo e até mesmo, em alguns casos, de alguns dos objetivos instrucionais.

A constituição desse currículo relativamente robusto, que pretende capacitar o futuro professor a identificar e receber alunos com necessidades educacionais especiais, conforme apontou Oliveira (2002), provendo-lhes ensino de qualidade, se deveu a uma particular história do campus de Marília no desenvolvimento da atenção a pessoas com deficiência. Convém discorrer brevemente sobre alguns dos fatos históricos relevantes para a compreensão do perfil da atual matriz curricular do curso de Pedagogia de Marília.

Com a criação da Universidade Estadual Paulista "Júlio de Mesquita Filho", em 1976, os cursos de Pedagogia dos antigos Institutos Isolados de ensino superior do Estado de São Paulo foram extintos, com exceção dos de Marília e Araraquara. Nesse ano, uma Comissão especialmente constituída para a elaboração de projeto de formação de professores especializados no ensino de deficientes na recém criada UNESP apresentou a proposta de implantação da Habilitação em Educação Especial, nas áreas de Deficiência Mental, Deficiência Visual, Deficiência Auditiva e Deficiência Física, no curso de Pedagogia de Marília. A Habilitação nas duas primeiras áreas foi implantada em 1977, a de Deficiência Auditiva em 1980 e a de Deficiência Física em 1989. Assim, ao cabo de 12 anos, as quatro áreas propostas haviam sido implantadas. Convém apontar que, antes mesmo de se iniciar a Habilitação em Educação Especial, já havia, no tronco comum do curso de Pedagogia de Marília, uma disciplina intitulada Introdução ao Estudo da Educação Especial, com 60 horas-aula, obrigatória para todos os alunos.

As disciplinas que compunham a Habilitação em Educação Especial estavam vinculadas a uma estrutura administrativa denominada Coordenação de Educação Especial, pois o Departamento ainda não havia sido criado por falta de massa crítica. Nove anos depois, tendo finalmente atendido as exigências em termos de quantidade mínima de professores com a titulação de doutor, foi criado, em 1985, o Departamento de Educação Especial ao qual as disciplinas da Habilitação em Educação Especial foram alocadas. A constituição do Departamento foi um marco importante para a consolidação da Habilitação em Educação Especial.

Em 1978, um grupo de professores iniciou discussóes sobre a possibilidade de atender as constantes solicitaçóes da comunidade local e regional demandando provisão de serviços de avaliação, orientação e assessoria com relação a problemas de aprendizagem apresentados por alunos da rede pública de ensino. Foi então proposta a criação do Centro de Orientação Educacional (COE), inicialmente vinculado ao Departamento de Psicologia da Educaçáo. Rapidamente os serviços prestados se ampliaram com aumento crescente de procura pela comunidade local e regional. O COE teve papel bastante importante para a consolidação da Habilitação em 
Educação Especial, pois a maior parte dos estágios supervisionados era realizada aí, com a possibilidade de os estudantes atuarem diretamente em atividades de avaliação, planejamento e intervenção, com a supervisão de professores do Departamento de Educação Especial. Em $1999^{8}$, o COE passou por profundas alteraçóes estruturais, mudando inclusive a denominação para Centro de Estudos da Educação e da Saúde (CEES) para incorporar parte dos estágios supervisionados do curso Fonoaudiologia. Posteriormente, alunos de Fisioterapia e de Terapia Ocupacional também passaram a realizar no CEES parte de seus estágios supervisionados.

A implantação dos cursos de Fonoaudiologia, em 1990, e de Fisioterapia e Terapia Ocupacional, em 2004, se constituiu em um importante marco para que as açóes pedagógicas praticadas em Educação Especial pudessem contar com o respaldo de três importantes subáreas da saúde, cuja necessidade de coatuação solidária no atendimento a pessoas com deficiência é inquestionável. A presença de estagiários desses cursos modificou expressivamente o panorama de serviços oferecidos no CEES a pessoas com deficiências e outras condiçóes especiais que impóem limitações ou impedimentos na realização de algumas atividades corriqueiras, fato esse que só veio fortalecer as ações pedagógicas praticadas em atenção a pessoas com deficiência.

A criação do Programa de Pós-Graduação em Educação, com linha de pesquisa Educação Especial no Brasil (atualmente Educação Especial), contribuiu para consolidar efetivamente a área da Educação Especial, no campus de Marília, em termos de pesquisa. O Programa teve início em 1988, apenas em nível de mestrado, e com o doutorado em 1993. As atividades de pesquisa em Educação Especial, no campus de Marília, que até então se restringiam aos compromissos contratuais dos professores do Departamento de Educação Especial, se expandiram com o início da pós-graduação stricto sensu.

Uma particularidade que pode ter contribuído decisivamente para a construção do perfil acadêmico do campus de Marília, com relação a questóes relativas à Educação Especial, foi a existência da Habilitação em Educação Especial, com quatro áreas de deficiências, sob a gestão de um único Departamento, o de Educação Especial. Essa condição criou uma situação privilegiada para se levantarem indagaçóes que dificilmente apareceriam em outros cursos de formação de professores especializados no ensino de deficientes, porque a maioria deles mantinha a Habilitação em uma única área de deficiência ${ }^{9}$. Mesmo quando havia Habilitação em duas áreas, como foi o caso da Faculdade de Educação da Universidade de São Paulo, as disciplinas estavam alocadas em diferentes Departamentos.

A atenção às pessoas com deficiência vem de uma longa tradição na qual os serviços habitualmente eram específicos para cada tipo de deficiência, sem muito diálogo entre os profissionais que atuavam em uma área de deficiência e os de outras áreas. Nessas condiçóes, pouca oportunidade havia para o questionamento das implicaçóes do fato de especializar por área de deficiência os serviços, a formação de profissionais, a construção e utilização de recursos,

\footnotetext{
${ }^{8}$ Em 1999, houve uma reestruturação curricular nos cursos de Pedagogia da UNESP que influenciaram a estruturação atual, entretanto esta discussão se encontra em outro texto específico da análise curricular do Curso de Pedagogia de Marília.

${ }^{9}$ Em Araraquara, apesar de a preocupação e as açôes relativas à atençáo a pessoas com deficiência terem começado muito cedo, a formação de professores de Educação Especial tomou rumos muito diferentes dos de Marília. Com a extinção da Habilitação em Educação Especial, reduziu-se drasticamente a presença de açốes em Educação Especial no seu curso de Pedagogia, limitando-se a uma única disciplina chamada Educação Especial, com 60 horas-aula. Essa trajetória pode ser devida, pelo menos em parte, ao fato de ter havido uma única área de deficiência, a de deficiência mental.
} 
o uso de métodos e técnicas de intervenção e a construção de conhecimentos por meio de pesquisas. A especialização por área de deficiência pode ter consequências no sentido de se atribuir à própria deficiência algumas dificuldades, limitaçóes ou impedimentos, que, na verdade, podem ser determinadas ou fortemente influenciadas por outras condiçôes compartilhadas por diferentes grupos minoritários. Com o foco em cada deficiência separadamente, muitos recursos e procedimentos podem ser subutilizados por serem considerados específicos para cada área de deficiência e inoperantes para outras áreas.

A oportunidade de os professores do Departamento de Educação Especial, no campus de Marília, de se defrontarem com indagaçóes daquela natureza e enfrentarem desafios para o equacionamento de problemas que não se limitavam a uma área específica de deficiência contribuiu decisivamente para a configuração do perfil acadêmico do Departamento de Educação Especial. O resultado disso pode ser visto, por exemplo, na ampliação progressiva da carga horária de disciplinas comuns a diferentes áreas de deficiência, apesar de a Habilitação em Educação Especial ser oferecida em áreas específicas. Na primeira turma, em 1977, eram apenas 60 horas-aula comuns às áreas de deficiência mental e deficiência visual, que estavam iniciando. As disciplinas comuns a todas as áreas de deficiência se ampliaram até chegar a 450 horas-aula, do total de 1230 a 1350 horas-aula da Habilitação dependendo da área de deficiência, na última turma, formada em 2010.

O campus de Marília é a única unidade da UNESP que possui o Departamento de Educação Especial e a linha de pesquisa em Educação Especial, no Programa de Pós-Graduação em Educação. Esse Departamento é responsável pela promoção do mais antigo evento científico da área, a Jornada de Educação Especial, que realiza a sua décima primeira edição em 2012. O grupo de professores de Marília luta pela preservação, mesmo com a extinção da Habilitação em Educação Especial, do patrimônio acadêmico construído nos 36 anos de trabalho. Foram criadas outras estratégias para a formação dos profissionais especializados: o Centro de Formação, Extensão e Pesquisa em Inclusão (CEFEPI) e o curso de especialização em Educação Especial, com 600 horas-aula sendo 200 de estágio supervisionado, que passa a ser oferecido em caráter regular.

Assim, a estruturação da matriz curricular do curso de Pedagogia de Marília, com disciplinas que fornecem fundamentos básicos e ferramentas para a atuação do professor no ensino de alunos com deficiência, na perspectiva inclusiva, teve forte influência dos pesquisadores que compóem o Departamento de Educação Especial, conforme apontou Oliveira (2009a). Segundo esse autor, não seria possível esperar que o mesmo ocorresse em outros cursos de Pedagogia do Brasil.

Se o pedagogo que se forma no curso de Marília pretender completar a sua formação para atenção a alunos com deficiência, pode realizar aprofundamento em Educaçáo Especial, com 570 horas-aula de disciplinas da Educação Inclusiva e Educação Especial, e em seguida, o curso de Especialização em Educação Especial, com 600 horas-aula, das quais 200 horas de estágio supervisionado, qualificando-se para a atuaçáo junto a alunos com deficiência. A Habilitação em Educação Especial tinha a carga horária variando de 1230 a 1350 horas-aula, dependendo da área de deficiência, com 300 horas de estágio supervisionado, a maior parte realizada no próprio CEES. Além da carga horária ligeiramente superior à soma das cargas 
horárias do aprofundamento e especialização em Educação Especial, a Habilitação era específica para cada deficiência. Caso algum pedagogo com Habilitação em Educação Especial em uma área de deficiência quisesse atuar junto a alunos com outras deficiências, era necessário cursar as disciplinas específicas dessas áreas. Portanto, pode-se sugerir que o modelo de Habilitação em Educação Especial do curso de Marília, que formou 32 turmas de professores especializados antes da sua extinção, pode capacitar melhor o pedagogo para desenvolver açóes educativas junto a alunos com deficiência, comparativamente às alternativas atuais.

Excluindo as possibilidades oferecidas no campus de Marília, os educadores formados nos cursos de Pedagogia da UNESP têm a possibilidade de assegurar a sua formação para atuação especializada junto a alunos com deficiência, por meio de disciplinas de graduação, cujas cargas horárias variam de 45 a 150 horas-aula, e de algum curso de especialização, cuja carga horária legalmente exigida é de 360 horas-aula. Esse quadro recomenda uma urgente reavaliação da nova situação criada pela recente deliberação do Governo Federal com relaçáo à reformulação dos cursos de Pedagogia e capacitação de educadores especializados no ensino de alunos com deficiência por meio de cursos de especialização.

Considerando as perspectivas atuais, talvez seja legítimo concluir que as recentes mudanças promovidas pelo Governo Federal representam uma perda expressiva em termos de formação de educadores especializados no ensino de alunos com deficiência. Ao mesmo tempo, podem representar um ganho expressivo em termos da formação de pedagogos em geral, com algum conhecimento acerca da Educação Inclusiva. A perda pode ser inexpressiva ou até inexistente, se essa avaliação se basear na idéia de que todas as crianças com deficiência devem (e podem) ser educadas em classes de ensino comum, regidas por professores que obtiveram algumas poucas noçóes básicas de Educação Inclusiva, e apenas excepcionalmente deve ser complementada a sua educação em salas de recursos multifuncionais, estas sob a responsabilidade de um educador especializado, formado com base em um elenco de diversificadas disciplinas com a carga horária total de 360 horas-aula, ou pouco mais que isso.

Conforme foi apontado na Introdução, a posição assumida pelos autores é a de que, com a inclusão, os recursos da Educação Especial, amplamente desenvolvidos ao longo de várias décadas de atenção educacional especializada a alunos com diferentes deficiências, devem ser criteriosa e exaustivamente utilizados para a provisão de ensino de qualidade a todos os alunos, inclusive aqueles com deficiências que podem requerer o uso de recursos diferenciados e muito especiais. Nesse sentido, ao lado da importância de se formarem pedagogos com conhecimentos acerca da Educação Inclusiva, há uma enorme necessidade, maior do que no passado, de se formarem educadores altamente especializados seja no conhecimento acerca das vicissitudes e particularidades de desenvolvimento e aprendizagem de crianças com deficiências seja no domínio de recursos especiais (materiais, equipamentos, métodos e técnicas etc.) capazes de atender as necessidades especiais desses alunos de tal maneira a prover-lhes ensino de melhor qualidade possível.

Por outro lado, se considerarmos a necessidade de todos os professores terem algum conhecimento acerca da Educação Inclusiva e eventualmente alguns recursos de Educação Especial, as Diretrizes Curriculares Nacionais instituídas pela Resolução CNE/CP no 1, de 15 de maio de 2006 (BRASIL, 2006) podem representar algum avanço, caso, como ocorreu 
com os cursos de Pedagogia da UNESP, em todo o território nacional esteja sendo incluída pelo menos uma disciplina que trata de questôes relativas à Educação Inclusiva nos currículos dos cursos de Pedagogia. Seria um avanço em relação a tentativas anteriores como aquela pretendida pelo MEC por intermédio da Portaria Ministerial no 1793, de 27 de dezembro de 1994 (apud CHACON, 2001), cuja recomendação para a inserção de uma disciplina que tratasse de "Aspectos ético-político-educacionais da normalização e integração da pessoa portadora de necessidades especiais", prioritariamente em cursos de Psicologia, Pedagogia e em todas as Licenciaturas, teve pouco efeito (CHACON, 2001).

Os coordenadores dos cursos de Pedagogia argumentaram que, mesmo existindo só uma disciplina sobre Educação Inclusiva, o tema poderia ser trabalhado de maneira transversal nas outras disciplinas, conforme alguns excertos a seguir:

[...] Daí não é só simplesmente aplicar uma disciplina, mas eu acho que as outras disciplinas também, de certo modo, têm que trabalhar com isso. Afinal é uma responsabilidade de todos nós. Temos que trabalhar isso, inclusive eu tenho que mostrar as contribuiçóes da psicologia em torno da questão de criar uma outra mentalidade de aprendizagem de perceber que todos têm condiçóes de aprender, mas dependendo da maneira que o professor conduza esse processo. P1 [...] a própria disciplina que eu ministro [aborda], [...] E os outros colegas também estấo trabalhando. P1

Educação Inclusiva é um tema, ela é uma perspectiva política. [..] Ela não tem que estar numa disciplina, ela tem que perpassar [...] P2.

[...] não vai haver a incorporação na forma de disciplinas novas, a idéia é que incorpore em termos de conteúdo. P2

[...] agora o processo vai ser de incorporar conteúdo de docente [...] P2

Quando você dá alfabetizaçáo, você tem que discutir crianças com diferenças na escola, não tem? P2

É na didática e nas metodologias, que não dá pra dar conteúdo metodologia e prática de ensino, se não tiver essa conversa da inclusão. Outra coisa que eles pedem é a história dos afrodescendentes [...] P3

Educação Inclusiva é uma disciplina que deveria não existir, que deveria ser um tema [...] transversal. P4

[...] Mais do que ter uma disciplina específica, eu considero como os professores pensam. Eu acredito que assim como na [disciplina de] psicologia, os colegas de sociologia, filosofia e história, todo mundo acaba tocando no tema. P6

A escolha de uma disciplina a ser incluída na matriz curricular não é fortuita, mas pode retratar a vontade política de um grupo de professores de quem depende a indicação e a aprovação. Se, além disso, muitos professores do corpo docente pensarem como os coordenadores entrevistados, de que a responsabilidade de transmitir aos futuros pedagogos as questôes relativas à inclusão escolar não compete a uma disciplina específica, mas deve ser compartilhada por professores que ministram diferentes disciplinas, então o resultado observado nos cursos de Pedagogia da UNESP, como decorrência das Diretrizes Curriculares Nacionais, pode representar um avanço político.

Novos estudos poderão investigar a compreensão do conceito de Educação Inclusiva por parte dos docentes dos cursos de Pedagogia da UNESP e as suas atitudes sociais em relação a inclusão. Poderá ser profícuo um estudo minucioso das ementas e dos planos de aula das disciplinas que compóem as matrizes curriculares, para a identificação de temas que tratam de 
questôes relacionadas a diferenças, inclusão e exclusão dos grupos minoritários em diferentes ambientes, direitos e deveres de toda a comunidade para a promoção da inclusão etc.

Faintanin, Costa e Ferraz (2009) apontaram que, se o curso de Pedagogia fornecer subsídios para uma formação crítica ao seu corpo discente, ele poderá, por meio das “experiências com seus alunos e da auto-reflexão crítica sobre sua ação pedagógica política” (p. 1548), direcionar o seu trabalho docente para "atitudes de sensibilidade e acolhimento da diversidade de seus alunos" (p. 1548).

Assim, espera-se que os cursos de Pedagogia da Universidade Estadual Paulista possam, ao longo dos quatros anos, formar seus estudantes para o domínio dos conceitos de inclusão escolar e construção de atitudes genuinamente favoráveis à inclusão, para que seus egressos sejam acolhedores em relação às diferenças e diversidades existentes na sala de aula.

\section{Conclusóes}

O curso de Pedagogia constituiu-se ao longo da história da educação, para hoje ser considerado o locus de formação dos profissionais que atuam na docência da Educação Infantil e dos anos iniciais do Ensino Fundamental, bem como na gestão de sistemas educacionais. Entretanto, essa definição de atuação dos pedagogos não se constituiu de maneira clara, calma e tranqüila. Embates políticos e epistemológicos ocorreram para a construção dessa definição do seu campo de atuação.

Essa legitimidade da identidade do pedagogo para a docência na Educação Infantil e nos cinco primeiros anos do Ensino Fundamental, bem como para atuar na gestão escolar, foi instituída pelas Diretrizes Curriculares Nacionais (BRASIL, 2006) para o curso de Pedagogia. Muitos debates se travam sobre essa identidade, é uma luta que compete a pedagogos e pesquisadores da área da Educação, com vistas a sua ampliação ou não.

Quanto à atuação do pedagogo em uma perspectiva inclusiva, sendo a Educação Inclusiva uma educação de qualidade que deve ser oferecida pelo sistema educacional a todas as crianças, jovens e adultos, com recursos, métodos e estratégias de ensino e, sobretudo, recursos humanos capacitados para atuarem como docentes na Educação Infantil, nos anos iniciais do Ensino Fundamental e como gestores dos Sistemas de Ensino, os cursos de Pedagogia da UNESP, excetuando o do campus de Marília, podem não estar preparando os professores para a Educação Inclusiva. Pelo conteúdo, carga horária e natureza isolada das poucas disciplinas incluídas nas matrizes curriculares, não nos parece que seus alunos recebam formação teórica e prática consistente para a compreensão da Educação Inclusiva no sentido que aqui lhe conferimos. 


\section{REFERÊNCIAS}

BRASIL. Ministério da Educação. Conselho Nacional de Educação. Resolução CNE/CP n ${ }^{\circ}$ 1, de 15 de maio de 2006. Institui Diretrizes Curriculares Nacionais para o curso de graduação em pedagogia, licenciatura. Diário Oficial da União, Brasília, DF, 16 maio 2006. Seção 1, p. 11.

. Ministério da Educação. Conselho Nacional de Educação. Resolução CFE nº. 2/69, de 12 de maio de 1969. Reformula o curso de Pedagogia e propóe habilitaçóes no último ano. Diário Oficial da União, Brasília, DF, 12 maio 1969.

. Presidência da República. Decreto-lei n. 1.190, de 4 de abril de 1939. Dá organização à Faculdade Nacional de Filosofia. Diário Oficial da União, Brasília, DF, 6 abril 1939. Seção 1, p. 7929.

. Presidência da República. Decreto-lei n. 4.024, de 20 de dezembro de 1961. Fixa Diretrizes e Bases da Educação Nacional. Diário Oficial da União, Brasília, DF, 27 dezembro 1961. Seção 1, p. 11429.

. Presidência da República. Decreto-lei n. 9.394, de 20 de dezembro de 1996. Estabelece as diretrizes e bases da educação nacional. Diário Oficial da União, Brasília, DF, 23 dezembro 1996. Seção 1, p. 27833.

CHACON, M. C. M. Formação de recursos humanos em educação especial: respostas das Universidades à recomendação da Portaria Ministerial n. 1.793 de 27.12.1994. 2001.161 f. Tese (Doutorado em Educação) - Faculdade de Filosofia e Ciências, Universidade Estadual Paulista, Marília, 2001.

FAITANIN, G. P. S.; COSTA, V. A.; FERRAZ, V. Formaçâo e Educação Inclusiva: as concepçôes do curso de Pedagogia/UFF á luz das atuais políticas públicas. In: CONGRESSO BRASILEIRO MULTIDISCIPLINAR DE EDUCAÇÃO ESPECIAL, 5., 2009, Londrina. Anais... Londrina: UEL, 2009. p. 1540-1549.

FONSECA-JANES, C. R. X. A formação dos estudantes de pedagogia para a Educação Inclusiva: estudo das atitudes sociais e do currículo. 2010. 269 f. Tese (Doutorado em Educação) - Faculdade de Filosofia e Ciências, Universidade Estadual Paulista, Marília, 2010.

LIBÂNEO, J. C. Pedagogia e pedagogos, para quê? São Paulo: Cortez, 1998. 200 p.

OLIVEIRA, A. A. S. Representaçôes sociais sobre educação especial e deficiência: o ponto de vista de alunos deficientes e professores especializados. 2002. 348 f. Tese (Doutorado em Educação) Faculdade de Filosofia e Ciências, Universidade Estadual Paulista, Marília, 2002.

. A política de formação de professores para educação especial: a ausência de diretrizes ou uma política anunciada. In: PINHO, S. Z. (Org.). Formaçâo de educadores: o papel do educador e sua formação. São Paulo: Editora UNESP, 2009a. il. p. 257-271.

. Educação especial: a formação do professor em debate. In: JORNADA DE EDUCAÇÃO ESPECIAL, 9., 2009, Marília. Resumos... Marília: Saepe, 2009b. p. 1-18.

OMOTE, S. Dificuldades e perspectivas para habilitação em Educação Especial. Revista Brasileira de Educação Especial, Marília, v. 2, n. 4, p. 127-135, 1996.

SAVIANI, D. Pedagogia: o espaço da educação na universidade. Cadernos de Pesquisa, São Paulo, v. 37, n. 130 , p. 1-16, abr. 2007.

UNIVERSIDADE ESTADUAL PAULISTA. Resolução da Unesp ño 16, de 29 de março de 2007.

Estabelece a estrutura curricular do Curso de Licenciatura em Pedagogia, da Faculdade de Ciências de Bauru. São Paulo, 2007a. 
Resolução da Unesp no 17, de 29 de março de 2007. Estabelece a estrutura curricular do Curso de Licenciatura em Pedagogia, da Faculdade de Filosofia e Ciências do Campus de Marília. São Paulo, 2007b.

Resolução da Unesp no 18, de 29 de março de 2007. Estabelece a estrutura curricular do Curso de Licenciatura em Pedagogia, da Faculdade de Ciências e Tecnologia do Campus de Presidente Prudente. São Paulo, 2007c.

Resolução da Unesp no 20, de 03 de abril de 2007. Estabelece a estrutura curricular do Curso de Licenciatura em Pedagogia, do Instituto de Biociências do Campus de Rio Claro. São Paulo, 2007d. Resolução da Unesp no 60, de 28 de agosto de 2007. Estabelece a estrutura curricular do Curso de Licenciatura em Pedagogia, da Faculdade de Ciências e Letras do Campus de Araraquara. São Paulo, 2007e.

. Resolução Unesp no 82, de 27 de novembro de 2007. Estabelece a estrutura curricular do Curso de Licenciatura em Pedagogia, do Instituto de Biociências, Letras e Ciências Exatas de São José do Rio Preto. São Paulo, $2007 f$.

. Resolução Unesp no 45, de 25 de Junho de 2009. Altera a Resolução UNESP no 82/07 que estabelece a estrutura curricular do Curso de Licenciatura em Pedagogia, do Instituto de Biociências, Letras e Ciências Exatas do Campus de São José do Rio Preto. São Paulo, 2009.

Recebido em: 07/05/2012

Reformulado em: 17/01/2012

Aprovado em: 30/03/2013 
FONSECA-JANES; C. R. X. \& OMOTE, S. 